\title{
TINJAUAN KEMAMPUAN PERAWATAN DAN PERBAIKAN ALSINTAN (ALAT DAN MESIN PERTANIAN) MASYARAKAT PETANI DI KAMPUNG MATARA MERAUKE
}

\author{
Andriyono", Andi Azizah ${ }^{2}$, Daniel Parenden ${ }^{3}$ \\ 1,3 Jurusan Teknik Mesin, Fakultas Teknik, Universitas Musamus \\ ${ }^{2}$ Jurusan Teknik Elektro, Fakultas Teknik, Universitas Musamus
}

Email: Andriyono1974@yahoo.co.id ; andiazizah_az@yahoo.co.id ;

dparenden@yahoo.com

\begin{abstract}
ABSTRAK
Beberapa permasalahan perawatan dan perbaikan Alsintan (Alat dan Mesin Pertanian) di Kampung Matara adalah minimnya pengetahuan petani dalam ketrampilan dan penguasaan perawatan alsintan. Jauhnya jarak yang harus ditempuh petani apabila ada kerusakan pada Alsintan menyebabkan mahalnya biaya perbaikan. Tujuan kegiatan penelitian adalah ingin mengetahui seberapa besar kemapuan petani dalam memperbaiki Alsintan yang rusak dan memberikan pengetahuan dan keterampilan bagi petani di Kampung Matara tentang cara perawatan Alsintan. Sehingga petani dapat melakukan perawatan pada Alsintan yang mereka miliki.

Penelitian ini dilakukan secara deskriptif dengan tahapan dari observasi, wawancara (petani dan ketua kelompok tani), pelatihan secara teori serta langsung mempraktekkan teknik perawatan dan perbaikan pada Alsintan milik petani yang ada.

Hasil penelitian di Kampung Matara terdapat oleh 2 kelompok Tani, antara lain; 1). Kelompok Tani Mayo 1, dan 2). Kelompok Tani Mayo 2 dengan jumlah peserta sebanyak 8 orang operator Alsintan (4 orang Kelompok Tani Mayo 1 dan 4 orang Kelompok Tani Mayo 2), 1 teknisi, 1 teknisi merangkap mahasiswa dan dalam penelitian melibatkan 3 orang mahasiswa jurusan teknik mesin Universitas Musamus. Dari hasil observasi dan wawancara diketahui hampir semua peserta belum terlalu mengetaui masalah perawatan dan perbaikan Alsintan, setelah yang pelatihan penguasaan materi oleh peserta pelatihan meningkat. Sedangkan Alsintan dari kelompok tani yang rusak dapat diperbaiki dan dioperasikannya. Alat-alat yang rusak baik rusak ringan, rusak sedang maupun yang rusak berat serta dapat digunakan secara langsung untuk menggarap sawah pada musim gaduhan.
\end{abstract}

Kata kunci : Alsintan, Perawatan, Perbaikan 


\section{PENDAHULUAN}

\section{A. Analisis Situasi}

Dalam rangka perwujudan Merauke sebagai Kota agropolitan oleh Pemda Kabupaten Merauke pada tahun 2004/2005, pembangunan di sektor pertanian mendapatkan perhatian yang sangat serius oleh pihak-pihak terkait. Termasuk di dalamnya adalah bidang mekanisasi pertanian, dengan pengadaan Alsintan, power trasher, dan lain sebagainya. Pengadaan unit-unit Alsintan merupakan salah satu peralatan yang sangat membantu dalam pengolahan lahan pertanian yang sangat luas namun terkendala dengan jumlah tenaga pengolah lahan yang sedikit. Hal ini juga didukung dengan jumlah pembukaan lahan pertanian yang selalu bertambah dari waktu ke waktu.

Kampung Matara yang berjarak kurang lebih $45 \mathrm{Km}$ dari pusat Kota adalah salah satu Kampung Lokal yang seluruh penduduknya adalah petani. Lahan persawahan yang ada di Kampung Matara adalah sawah tadah hujan yang hanya ditanami maksimal 2 kali dalam setahun.

Seperti halnya petani lokal di daerah lain, petani di Kampung Matara mendapatkan bantuan Alsintan yang dikelola oleh Kelompok-kelompok tani yang ada di Kampung Matara. Adapun data bantuan alsintan yang diberikan pemerintah dapat dilihat pada tabel berikut.

Tabel 1. Data Alsintan yang Dimiliki Petani di Kampung Matara.

\begin{tabular}{|c|l|c|c|l|l|}
\hline No. & Nama Alat & $\begin{array}{c}\text { Tahun } \\
\text { Pengadaan }\end{array}$ & Jumlah & Pengelola & Keterangan \\
\hline 1. & Power trasher & 2011 & 2 & $\begin{array}{l}\text { Kelompok } \\
1\end{array}$ & Rusak berat \\
\hline 2. & Hand traktor & 2010 & 2 & $\begin{array}{l}\text { Kelompok } \\
1,2\end{array}$ & Rusak sedang \\
\hline 3. & Pompa Air & 2012 & 2 & $\begin{array}{l}\text { Kelompok } \\
2\end{array}$ & Rusak sedang \\
\hline 4. & Bajak singkal & 2010 & 2 & $\begin{array}{l}\text { Kelompok } \\
1,2\end{array}$ & Rusak ringan \\
\hline 5 & Bajak Rotari & 2010 & 2 & $\begin{array}{l}\text { Kelompok } \\
1,2\end{array}$ & Rusak Berat \\
\hline
\end{tabular}

Dari total jumlah Alsintan yang ada, seluruhnya dimiliki oleh petani lokal. Tetapi kurang didukung oleh perawatan yang baik, hal ini disebabkan oleh minimnya pengetahuan dan ketrampilan para petani dalam melakukan perawatan terhadap Alsintan yang mereka miliki. Sehingga semua Alsintan yang ada dalam keadaan tidak siap digunakan dalam menghadapi musim tanam yang akan datang. Padahal Alsintan yang ada masih tergolong baru. Oleh karena itu diperlukan adanya bimbingan kepada para petani tentang cara perawatan pada hand traktor yang dimiliki. Kondisi tersebut merupakan tantangan bagi Fakultas Teknik UNMUS sebagai institusi pendidikan tinggi untuk memperpendek jarak dalam proses inovasi teknologi perawatan peralatan yang dimiliki petani dengan memberikan kesempatan kepada staf pengajar dan mahasiswa untuk mampu mengembangkan dan mengimprovisasikan bekal penelitian dan penelitian yang dapat diterapkan di masyarakat.

\section{B. Tujuan Kegiatan}

Tujuan Kegiatan ini diharapkan adalah memberikan pengetahuan dan ketrampilan kepada petani tentang perawatan dan perbaikan alsintan.

\section{Manfaat Kegiatan}

Kegiatan penelitian kepada masyarakat ini diharapkan memiliki manfaat antara lain:

1. Terawatnya Alsintan yang dimiliki oleh masayarakat kampung Matara.

2. Membantu petani menyiapkan Alsintan mereka untuk menghadapi musim tanam.

3. Dapat dijadikan media praktikum bagi mahasiswa Jurusan Teknik Mesin terutama bagi mahasiswa yang terlibat langsung dalam kegiatan penelitian ini sehingga menambah ketrampilannya.

Pelatihan yang dilakukan di dalam kelas meliputi pengenalan bagian-bagian Alsintan secara menyeluruh. Bahan dalam bentuk modul diberikan kepada setiap peserta. Selain dalam bentuk modul, pada saat pengenalan di kelas, peserta juga diajak langsung melihat pada alat yang dibawa ke dalam ruangan sebagai peraga 
agar peserta lebih mudah mengenali bagianbagian dari Alsintan.

Selain pengenalan bagian-bagian Alsintan, kegiatan yang dilakukan di dalam ruang kelas juga berupa keterangan-keterangan lain seputar kegiatan pemeriksaan awal alat sebelum dioperasikan dan perawatan sederhana yang harus dilakukan.

Setelah diberikan bekal berupa pengenalan di dalam kelas, peserta kemudian peserta pelatihan dituntun untuk melakukan sendiri kegiatan-kegiatan seperti yang telah diberikan dalam kelas. Kegiatan percontohan ini diberikan selama terus menerus selama pelatihan di lapangan.

Setelah kegiatan pelatihan, tetap dilakukan pendampingan dalam kegiatan perawatan mesin Alsintan disamping kegiatan lainnya seperti perbaikan alat yang rusak. Selain berupa pendampingan langsung ke Matara, petani juga dapat langsung datang ke kampus. Diharapkan pula dengan telah dilakukannya kegiatan ini, masyarakat merasa lebih dekat dengan kehidupan kampus.

Pelatihan di dalam kelas dilaksanakan di balai pertemuan sedangkan praktek dilaksanakan di rumah ketua kelompok tani masing-masing.

Universitas Musamus Merauke melalui Lembaga Penelitian dan Penelitian kepada Masyarakat ( $\left.\mathrm{LP}_{2} \mathrm{M}\right)$ telah mengadakan kerjasama dan koordinasi eksternal antara lain mengadakan sosialisasi dan pelatihan penyusunan proposal PPM bagi dosen dengan mendatangkan beberapa pakar yang berpengalaman dalam bidang penyusunan artikel ilmiah. Selain itu untuk mengimplementasikan hasil-hasil penelitian terhadap masyarakat lokal maka LP2M Universitas Musamus Merauke telah menjalin kontrak kerja sama dengan 14 (empat belas) kampung lokal sebagai kampung binaan UNMUS pada tanggal 11 Pebruari 2011.

Kegiatan yang dilaksanakan ini $\begin{array}{lll}\text { mengaitkan } & \text { program }\end{array}$ dalam pembinaan Kampung lokal melalui Penelitian dan Pelatihan perawatan alsintan. Untuk itu LP2M sangat mendukung program ini karena bersentuhan langsung dengan upaya pembinaan masyarakat Kampung Matara yang merupakan salah satu Kampung Lokal. Pelaksanaan kegiatan di Kampung Matara dilaksanakan dalam bentuk tim yang terdiri atas satu ketua dengan bidang keahlian Teknik Konstruksi Mesin dan satu anggota dengan bidang keahlian Teknik Pertanian serta didukung oleh dua orang teknisi dengan bidang keahlian teknik mesin dan seorang mahasiswa jurusan keteknikan pertanian. Perpaduan beberapa bidang keahlian ini diharapkan memberikan hasil yang optimal karena sesuai dengan kondisi kegiatan di lapangan.

\section{HASIL DAN LUARAN YANG DICAPAI}

Kegiatan ini dilaksanakan melakukan survey dan rapat internal dengan Ketua Kelompok Tani Mayo 1 dan Mayo 2 bertempat dirumah bapak Ibrahim Pakalessy. Hal ini bertujuan untuk menyampaikan halhal teknis tentang kegiatan pelatihan yang akan dilaksanakan, menentukan jumlah peserta, menentukan waktu pelaksanaan pelatihan, tempat kegiatan dan mendata ulang alat-alat yang kan dipakai untuk pelatihan.

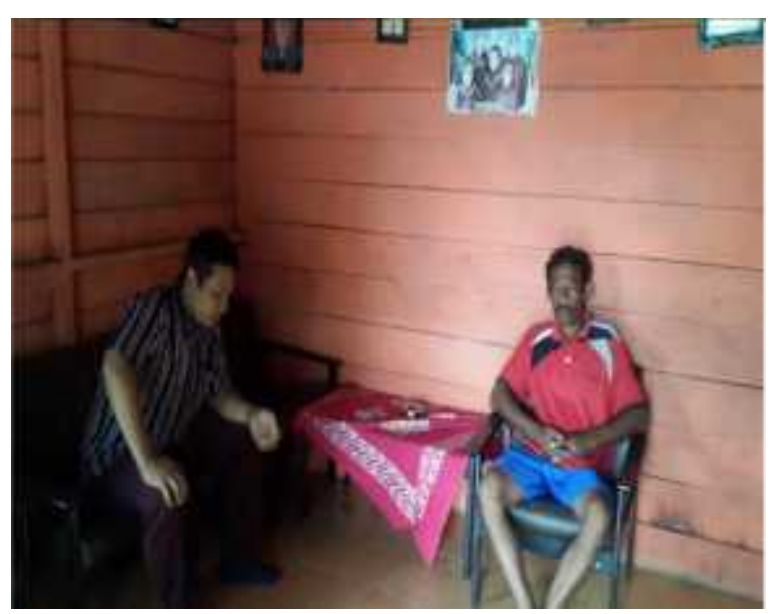

Gambar 1. Kegiatan diskusi dengan ketua kelompok Tani dan Survey. 
Dari hasil survey ini diperoleh data - data tentang jumlah alsintan yang akan dipergunakan sebagai media praktek yaitu:

Tabel 2. Data Alsintan yang Dimiliki Petani di Kampung Matara dari hasil survey.

\begin{tabular}{|c|c|c|c|c|c|}
\hline No & Nama Alat & $\begin{array}{l}\text { Tahun } \\
\text { Pengadaan }\end{array}$ & Jumlah & Pengelola & Keterangan \\
\hline 1 & $\begin{array}{l}\text { Power } \\
\text { trasher }\end{array}$ & 2011 & 2 & $\begin{array}{l}\text { Kelompo } \\
\mathrm{k} 1,2\end{array}$ & Rusak berat \\
\hline 2 & $\begin{array}{l}\text { Hand } \\
\text { traktor }\end{array}$ & 2010 & 5 & $\begin{array}{l}\text { Kelompo } \\
\mathrm{k} 1,2\end{array}$ & $\begin{array}{l}\text { Rusak } \\
\text { sedang }\end{array}$ \\
\hline 3 & Roda besi & 2012 & 8 & $\begin{array}{l}\text { Kelompo } \\
\mathrm{k} 1,2\end{array}$ & $\begin{array}{l}\text { Rusak } \\
\text { sedang }\end{array}$ \\
\hline 4 & $\begin{array}{l}\text { Bajak } \\
\text { singkal }\end{array}$ & 2010 & 4 & $\begin{array}{l}\text { Kelompo } \\
\mathrm{k} 1,2\end{array}$ & $\begin{array}{l}\text { Rusak } \\
\text { ringan }\end{array}$ \\
\hline 5 & Garu & 2010 & 3 & $\begin{array}{l}\text { Kelompo } \\
\mathrm{k} 1,2\end{array}$ & $\begin{array}{l}\text { Rusak } \\
\text { sedang }\end{array}$ \\
\hline 6 & Glebek & 2010 & 4 & $\begin{array}{l}\text { Kelompo } \\
\mathrm{k} 1,2\end{array}$ & $\begin{array}{l}\text { Rusak } \\
\text { Berat }\end{array}$ \\
\hline
\end{tabular}

Terjadi penambahan alat mesin pertanian yang akan dipakai sebagai sarana praktek, hal ini disebabkan jangka waktu pelaksanaan pengusulan dan realisasi pelaksanaan kegiatan berjarak kurang lebih 16 bulan. Namun demikian hal ini tidak mengganggu persiapan maupun tahapantahapan yang akan dikerjakan. Hanya saja dikarenakan penambahan jumlah alsintan yang diperbaiki ini, membuat pembengkakan jumlah material dan bahan maupun jumlah hari pelaksanaan kegiatan yang semula direncanakan 5 hari menjadi 8 hari kerja sehingga menambah jumlah pembiayaan kegiatan.

Tahapan selanjutnya dari kegiatan ini adalah mempersiapkan materi untuk pelatihan serta peralatan - peralatan yang akan digunakan. Beberapa peralatan yang akan digunakan memerlukan perbaikan, diantaranya pengelasan palu, stang las dan kunci-kunci untuk membuka baut roda traktor. Untuk pelatihan pengelasan dan perawatan perbaikan alat-alat pertanian seperti perontok padi dan roda bebek hand traktor bagi operator diperlukan bahan-bahan antara lain, plat $5 \mathrm{~mm}$, plat $3 \mathrm{~mm}$, plat $2 \mathrm{~mm}$ serta batu gurinda untuk memotong-motong bahan plat tersebut.

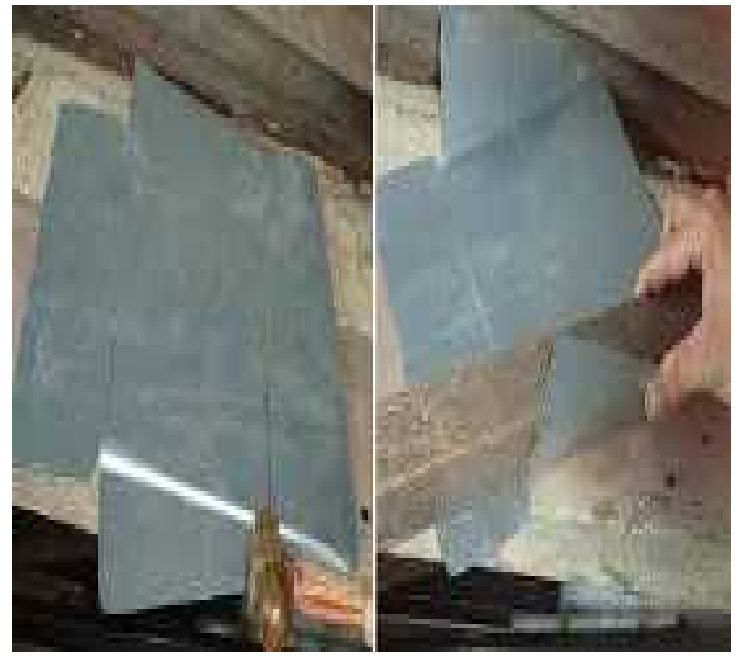

Gambar 2. Perbaikan palu dan pengadaan plat besi

Pelatihan mulai dilaksanakan bagi para operator dan juga beberapa mahasiswa. Jumlah peserta adalah 15 orang yang terdiri dari 8 orang operator Alsintan, 1 orang Teknisi, 1 orang Teknisi/mahasiswa, 3 orang mahasiswa.pada awal pelatihan ini lebih ditekankan pada materi praktikum dan manual book dari Alsintan itu sendiri.

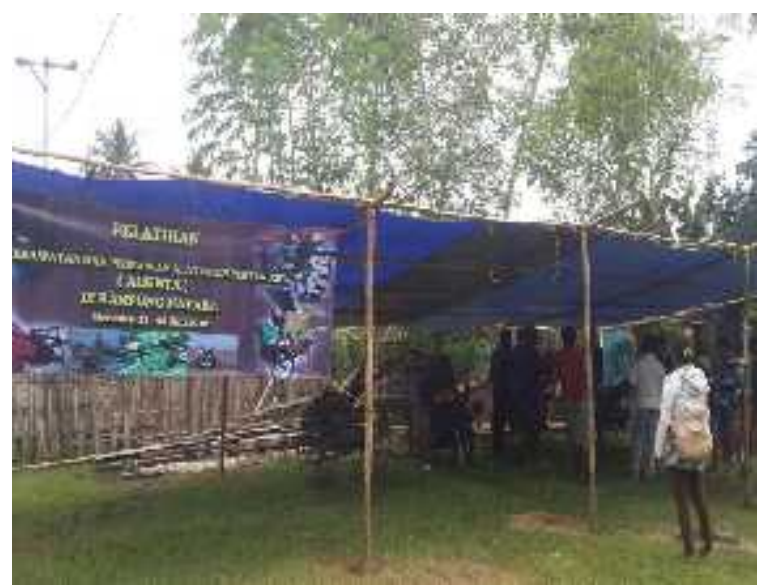

Gambar 3. Pembekalan Materi Pelatihan Dan Perbaikan Peserta Pelatihan

Untuk kegiatan dilaksanakan didepan rumah bapak Ibrahim Pakallessy (Ketua Kelompok Tani Mayo1). Pembuatan tenda ini membutuhkan terpal serta membeli engsel dan grendel untuk perbaikan mesin perontok padi. Dengan bergotong royong, tempat untuk melaksanakan pelatihan akhirnya dapat diselesaikan. Tidak lupa juga membeli Olie mesin dan olie gardan untuk 6 unit traktor. 
Sebagai konsumsi, dikarenakan pelatihan yang dilaksanakan berjalan satu hari (dari jam $08.00 \mathrm{~s} / \mathrm{d}$ 16.00), para peserta pelatihan disiapkan snack (makanan kecil) sebanyak 2 kali dan makan siang 1 kali. Peserta sangat antusias dalam menerima materi tentang manual book alsintan maupun materi tentang pengelasan dan system bongkar pasang gearbox hand traktor. Materi tentang K3 juga diberikan sebagai materi tambahan untuk peserta dan mahasiswa.

Pelatihan hari kedua kali ini mulai dengan pembongkaran 5 unit Hand traktor serta perbaikan mesin perontok padi. Untuk keperluan kegiatan ini diperlukan pengadaan Mesin Las dan Mesin gurinda tangan untuk memperlancar praktek bagi peserta pelatihan.

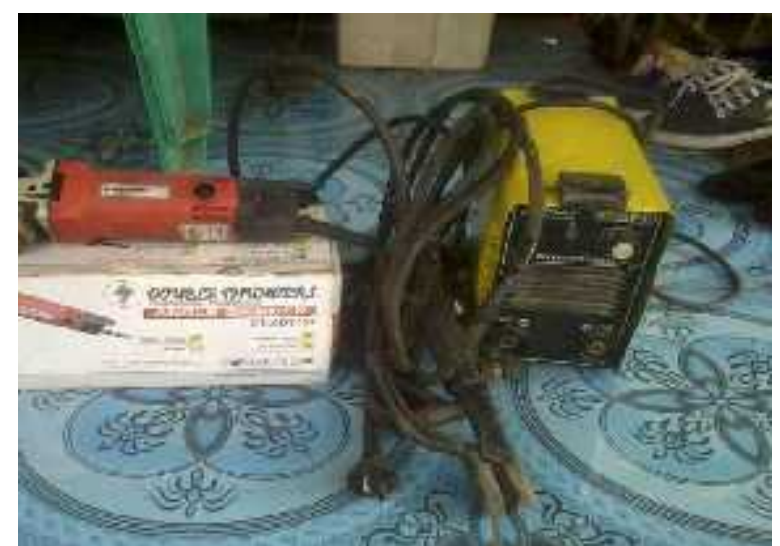

$$
\begin{gathered}
\text { Gambar 4. Travo Las dan Gurinda } \\
\text { Tangan }
\end{gathered}
$$

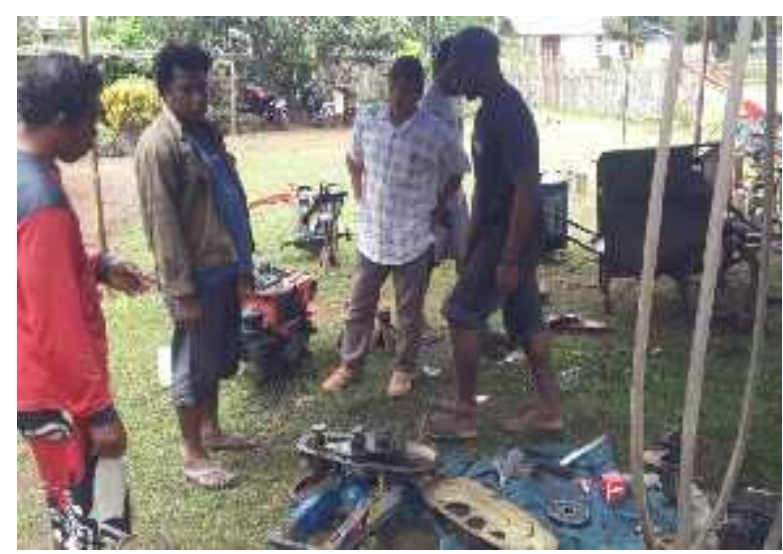

Gambar 5. Pembongkaran Gearbox

Pelatihan hari ke-3. Setelah dilakukan pembongkaran dan pengamatan, didapatkan beberapa komponen dari Hand Traktor perlu diganti. Untuk itu perlu diadakan pengadaan komponen-komponen tersebut.

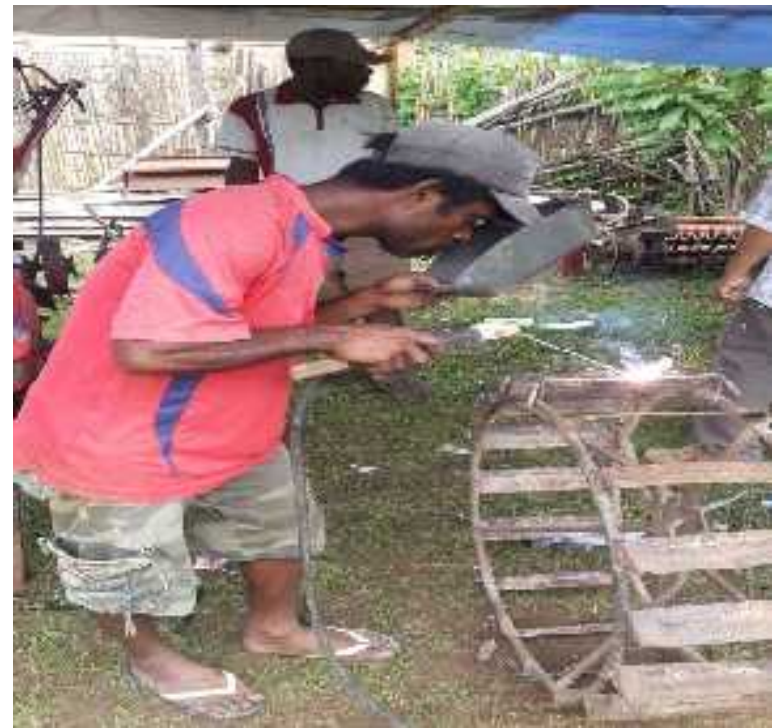

Gambar 6. Praktek Mengelas

Pelatihan hari ke-4. Pelaksanaan pelatihannya dengan meneruskan pelatihan yang kemarin dengan memindahkan beberapa peserta dari pelatihan bongkar pasang Gearbox ke pelatihan pengelasan dan sebaliknya.

Pelatihan hari ke-5. Pada hari ini pelatihan difokuskan pada pemasangan dan penggantian komponen-komponen yang harus diganti serta pelatihan pengelasan difokuskan untuk memperbaiki mesin perontok padi.

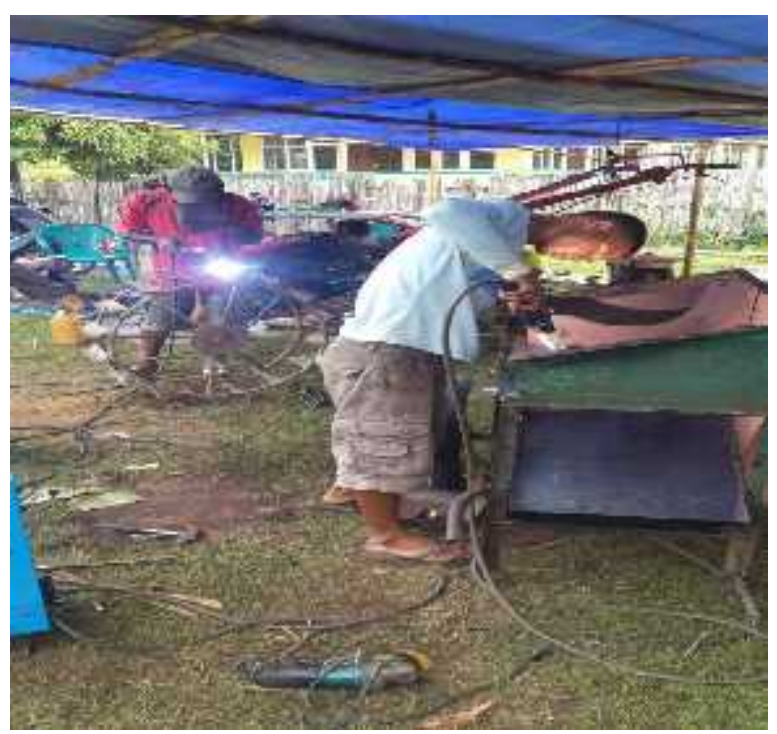

Gambar 7. Penggantian sparepart dan pengelasan Perontok Padi 
Pelatihan hari ke-6. Dengan agenda pelatihan melanjutkan bongkar pasang Gearbox dan pelatihan pengelasan. Pelatihan dilanjutkan pada pelatihan perawatan dan perbaikan Mesin Penggerak dari hand traktor yaitu mesin Kubota RD 85 serta mesin penggerak perontok padi R-175. Setelah dilakukan pengecekan pada mesin penggerak, ada beberapa komponen yang perlu diganti, diantaranya Ring seher, Metal dan beberapa peralatan yang lainnya..

Pelatihan hari ke-7. Melanjutkan pelatihan kemarin, yaitu pelatihan bongkar pasang mesin Penggerak Hand traktor Kubota RD 85. Dalam pelaksanaan pelatihan ini peserta dipandu untuk dapat melepas dan mengganti komponen yang rusak dengan prosedur yang benar.

Pelatihan hari ke 8. Pelatihan ini difokuskan pada uji coba pengoperasian semua alsintan yang telah dipakai untuk praktek, yaitu Gearbox 5 unit Hand traktor, 3 unit Mesin penggerak Hand traktor, Body perontok padi serta mesinnya. Adapun untuk praktek Pengelasan diterapkan pada roda besi hand traktor sebanyak 6 pasang dan juga pada penggentian dinding-dinding mesin perontok padi.

Dari hasil kegiatan pelatihan dan praktek secara langsung oleh para peserta dan teknisi selama 8 (delapan) hari diperoleh alat-alat yang selesai diperbaiki dan dapat dioperasikan adalah sebagai berikut:

Tabel 3. Data Alsintan yang selesai diperbaiki dan dapat dioperasikan.

\begin{tabular}{|c|c|c|c|c|l|}
\hline No. & Nama Alat & $\begin{array}{c}\text { Tahun } \\
\text { Pengadaan }\end{array}$ & Jumlah & Pengelola & Keterangan \\
\hline 1 & Power trasher & 2011 & 2 & $\begin{array}{l}\text { Kelompok } \\
1,2\end{array}$ & Normal \\
\hline 2 & Hand traktor & 2010 & 5 & $\begin{array}{l}\text { Kelompok } \\
1,2\end{array}$ & Normal \\
\hline 3 & Roda besi & 2012 & 8 & $\begin{array}{l}\text { Kelompok } \\
1,2\end{array}$ & Normal \\
\hline 4 & Bajak singkal & 2010 & 4 & $\begin{array}{l}\text { Kelompok } \\
1,2\end{array}$ & Normal \\
\hline 5 & Garu & 2010 & 3 & $\begin{array}{l}\text { Kelompok } \\
1,2\end{array}$ & Normal \\
\hline 6 & Glebek & 2010 & 4 & $\begin{array}{l}\text { Kelompok } \\
1,2\end{array}$ & Normal \\
\hline
\end{tabular}

Hasil dari kegiatan ini telah diaplikasikan secara langsung dilapangan. Penggunaan Alsintan hasil kegiatan sudah digunakan untuk mengolah hasil pertanian dan mengolah lahan untuk musim gaduh.

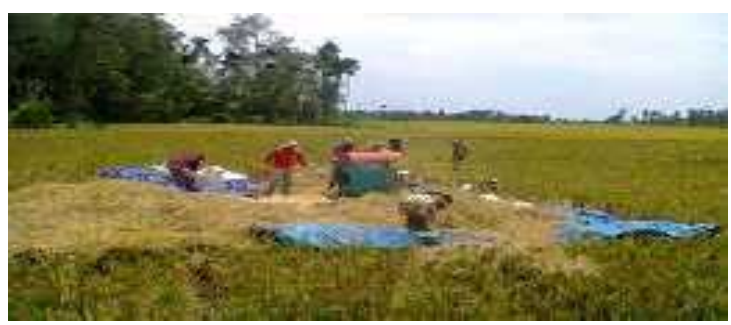

Gambar 8. Penerapan Mesin perontok padi

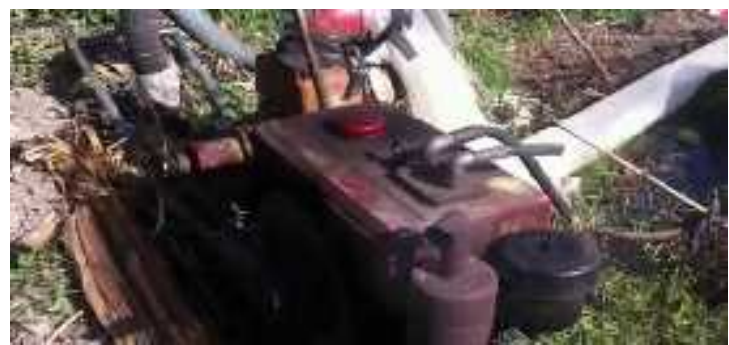

Gambar 9. Penggunaan pompa air untuk tanam gaduh

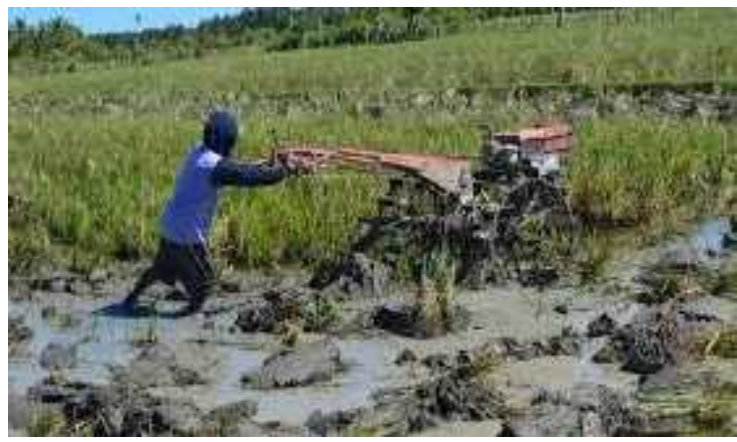

Gambar 10. Olah Lahan

Berdasarkan rencana tindak lanjut yang disusun pada saat kegiatan, maka rencana tahapan berikutnya adalah menindaklanjuti aplikasi di lapangan pada musim rendeng Tahun 2016 dengan mengaplikasikan dan mempraktekkan Alsintan di lahan persawahan dan mengamati serta mengukur seberapa besar manfaat dari kegiatan pelatihan dan perbaikan Alsintan Kelompok Tani Mayo 1 dan Mayo 2. Kegiatan akan dilakukan dengan mengevaluasi dan menghitung lahan sawah yang dapat dikerjakan oleh operator Alsintan serta 
membimbing para operator dalam menerapkan tata cara pengoperasian Alsintan yang benar serta mempraktekkan cara pengelasan yang baik dan benar.

\section{KESIMPULAN}

Kegiatan pelatihan Perawatan dan Perbaikan Alat-alat Mesin Pertanian ini bertempat di Kampung Matara Distrik Semangga Merauke, dapat terlaksana dengan baik dengan diikuti oleh 2 kelompok Tani, Kelompok Tani Mayo 1 dan kelompok Tani Mayo 2 dengan jumlah peserta sebanyak 8 orang operator Alsintan (4 orang Kelompok Tani Mayo 1 dan 4 orang Kelompok Tani Mayo 2), 1 teknisi, 1 teknisi merangkap mahasiswa dan 3 orang mahasiswa. Hasil yang diperoleh adalah penguasaan materi oleh peserta pelatihan dengan dapat diperbaiki dan dioperasikannya. alat-alat yang rusak baik rusak ringan, rusak sedang maupun yang rusak berat serta dapat digunakan secara langsung untuk menggarap sawah pada musim gaduhan.

Saran dari kegiatan pelatihan perawatan dan perbaikan Alsintan ini agar lebih diperbanyak/diintensifkan lagi mengenai jumlah peserta maupun kualitas pendukung pelatihan yang nantinya akan dihibahkan bagi para peserta (kelompok tani) sebagai mitra kerja dan sebagai mitra binaan, agar ilmu dan ketrampilan yang diperoleh bisa dipertahankan dan dikembangkan lagi secara mandiri, berkualitas dan berdaya saing.

\section{DAFTAR PUSTAKA}

1]. Manual Book Traktor Rotary Quick Zena Multi Speed.

2]. Manual Book, Pompa Air Honda GX160.

3]. Peraturan Menteri Pertanian Nomor: 25/Permentan/Pl.130/5/ 2008 Tentang Pedoman Penumbuhan Dan Pengembangan Usaha Pelayanan Jasa Alat Dan Mesin Pertanian.

4]. Sebayang, T. Analisis Sistem Unit Pelayanan Jasa Alsintan (UPJA) dan Dampaknya Terhadap Pengembangan Ekonomi, Fakultas Pertanian Jurusan Sosial
Ekonomi Universitas Sumatera Utara, Medan.

5]. Team RB, Pengoperasian dan perawatan Hand Traktor (traktorTangan). BPT Mekanisasi Pertanian Jawa Barat Dinas Pertanian Jawa Barat. 